The same value of $x$ being a root of both equations we have the following theorem :-A root of the equation

$$
-\sqrt{ }\{(x-a)(x-b)\}+\sqrt{ }\{(x-c)(x-d)\}=e
$$

is also $a$ root of the equation

$$
\sqrt{ }\{(x-a)(x-b)\}+\sqrt{ }\{(x-c)(x-d)\}=\{(a+b-c-d) x-a b+c d\} / e
$$

or, elimitating $x$ by means of (4) from the right-hand side of this last equation, it is a root of the equation

$$
\begin{aligned}
& \sqrt{ }\{(x-a)(x-b)\}+\sqrt{ }\{(x-c)(x-d)\} \\
& =e\{\mathrm{P}(\mathrm{P}+\mathrm{Q}+\mathrm{R})-4 a\} / \Pi \pm 2 \mathrm{P} \sqrt{ }(\mathbf{L M}) / \Pi,
\end{aligned}
$$

the ambiguity of sign being properly chosen.

Example.-We have seen that $x=9 \cdot 4295 \ldots$ is the root of the equation

$$
-\sqrt{ }\{x(x-3)\}+\sqrt{ }\{(x-2)(x-9)\}=-6 ;
$$

whence we find that the same value of $x$ is the root of the equations

and

$$
\begin{aligned}
& \sqrt{ }\{x(x-3)\}+\sqrt{ }\{(x-2)(x-9)\}=\frac{4}{3} x-3, \\
& \sqrt{ }\{x(x-3)\}+\sqrt{ }\{(x-2)(x-9)\}=\frac{3}{5}(5+2 \sqrt{ } 30) .
\end{aligned}
$$

Fourth Meeting, February 13, 1891.

R. E. Allardice, Esq., M.A., F.R.S.E., President, in the Chair.

\title{
A problem in the theory of numbers.
}

By T. Hugh Miller, M.A.

Let it be required to find the square integral numbers which added to a given integer shall produce a square integer, and the smallest such number.

Let $\mathrm{N}$ be the given number, and let the sum of $\mathrm{N}$ and $x^{2}$ be $y^{2}$, where $i$ and $y$ are integers.

Then

$$
\mathrm{N}=y^{2}-x^{2}=(y+x)(y-x) .
$$

Now resolve $\mathrm{N}$ into its prime factors, let these $l^{a} m^{b} n^{c} \ldots$. Then if $y+x$ is put equal to the product of any number of these factors, and $y-x$ equal to the product of all the others, a series of values of $y$ is obtained. 
If the factor 2 is one of the factors of $\mathrm{N}$, and of the first degree, then 2 must be a factor of $y+x$ or of $y-x$ only. Therefore $y$ and $x$ cannot be integers. Thus if $\mathrm{N}$ is double of an odd number it is impossible to find a solution. If 2 is one factor it must be of at least the second degree.

If $\mathrm{N}$ is a square number, $x=0$ is obviously one solution, and the least.

Excluding these values, we may put $x+y$ equal to a series of values the number of which is

$$
1+a+b+c \ldots+a b+a c+b c+\ldots+a b c+\ldots .
$$

Now one half of these values are greater than $\sqrt{ } \mathbf{N}$, and since $y+x$ is always greater than $y-x$, the number of solutions is

$$
\frac{1}{2}(1+a)(1+b)(1+c) \ldots
$$

Since $a, b, c$ are by hypothesis not all even numbers, this number is of course an integer.

If the least value of $x$ is required, $y+x$ and $y-x$ must differ by as swall a number as possible. Then $y+x$ must be taken equal to the product of those prime factors of $\mathrm{N}$, which differs from $\sqrt{ } \mathrm{N}$ by as small a number as possible, and is greater than $\sqrt{ } \mathrm{N}$.

For example. It is impossible to add a square number to 6 so that the sum shall be a square.

Let the given number be 525 .

Now $525=35 \% 7$, thus putting $y+x=5^{2}$, and $y-x=21$, we get $x=2, y=23$.

$$
\therefore \quad 525+2^{2}=23^{2} \text {. }
$$

There are in all $\frac{1}{2} \times 2 \times 3 \times 2$, that is 6 solutions; the other numbers to be added being

$$
10^{2}, 34^{2}, 50^{2}, 86^{2}, 262^{2} \text {. }
$$

If $2^{4}$ is one of the factors of $\mathrm{N}$, since 2 must be a factor of $y+x$, and of $y-x$, the number of solutions is

$$
\frac{1}{2}(1+a-2)(1+b)(1+c) \ldots \ldots .
$$

For example, let $\mathrm{N}=1000$, that is $2^{3} \cdot 5^{3}$. There are $\frac{1}{2}(3-1)(1+3)$ that is 4 solutions. It is sufficient to consider the factors $2.5^{3}$, as 2 must be a factor of $y+x$ and $y-x$. Then putting $y+x=5^{2}$, and $y-x=2 \times 5$, we get $15^{2}$ as the smallest square required.

In a similar way the least value of $\mathrm{N}$ can be found which will 
make $\mathrm{N}^{2}+a \mathrm{~N}$ a square integer, where $a$ is a given constant. For putting the expression equal to $y^{2}$

$$
\mathrm{N}=\left\{-a+\sqrt{(}\left(a^{2}+4 y^{2}\right)\right\} / 2,
$$

and the problem is reduced to that of finding the least square of an even number which added to $a^{2}$ will make it an integral square.

If $a$ is an even number, $\mathrm{N}$ is obviously an integer. If $a$ is odd, $\sqrt{ }\left(a^{2}+4 y^{2}\right)$ is also an odd number, and therefore $\mathrm{N}$ is again an integer.

\section{Sur un Lieu Góométrique.}

\section{Par M. Paul Aubert.}

Par un point fixe A d'une circonférence donnée on mèné deux cordes $\mathrm{AB}$ et $\mathrm{AC}$ dont le produit a une valeur constante $\mathrm{m}^{2}$, puis on joint $\mathrm{BC}$. Trouver $1^{\circ}$ le lieu du pied $\mathrm{D}$ de la bissectrice de l'angle A du triangle $\mathrm{ABC} ; 2^{\circ}$ le lieu des centres des cercles inscrits et exinscrits à ce triangle.

\section{Figure 14.}

$1^{\circ}$. Soit $\mathrm{H}$ le point où la bissectrice $\mathrm{AD}$ rencontre la circonférence circonscrite au triangle $\mathrm{ABC}$.

$$
\begin{aligned}
\text { On sait que } & \mathrm{AD} \times \mathrm{AH} & =\mathrm{AB} \times \mathrm{AC} ; \\
\text { donc on a } & \mathrm{AD} & =m^{2} / \mathrm{AH} .
\end{aligned}
$$

Ie lieu du point $\mathrm{D}$ est la figure inverse de la circonférence lieu de $H$, le pôle d'inversion étant en $A$, la puissance d'inversion $m^{2}$. C'est donc la perpendiculaire $\mathrm{XY}$ au diamètre $\mathrm{AO}$; elle coupe la circonférence aux points $F$ et $G$ tels que

$$
\mathrm{AF}=\mathrm{AG}=m \text {. }
$$

$2^{\circ}$. Si on mène $B K$ parallèle à $X Y$, les arcs $A F B$ et $A C K$ sont égaux, d'où $\angle \mathrm{ACB}=\angle \mathrm{AB}^{\prime} \mathrm{C}^{\prime}$.

Les droites $B C$ et $B^{\prime} C^{\prime}$ sont alors anti-parallèles, et $A D$ est bissectrice de l'angle $\mathrm{B}^{\prime} \mathrm{DC}$. Par suite le cercle inscrit au triangle $A B C$ est aussi inscrit au triangle $A B^{\prime} C^{\prime}$, et il en est de même du cercle ex-inscrit dans l'angle $A$. D'ailleurs on a manifestement

$$
\text { d'où } \quad \begin{array}{ll}
\mathrm{AB}^{\prime}=\mathrm{AC}, \mathrm{AC}^{\prime} & =\mathrm{AB}, \\
\mathrm{AB}^{\prime} \times \mathrm{AC}^{\prime} & =m^{2} .
\end{array}
$$

Lo problème revient donc à considérer les triangles tels que 